\title{
Research Involvement Among Undergraduate Health Profession Students in a Resource-Limited Setting: Awareness, Attitude, Motivators and Barriers
}

Blaise Kiyimba ( $\nabla$ blaisekiym12@gmail.com )

Makerere University

Linda Atulinda

Makerere University

Racheal Nalunkuma

Makerere University

Ignatius Asasira

Makerere University

Jonathan Kabunga

Makerere University

Davis Banturaki

Makerere University

Anastacia Ssebbowa Nabyonga

Makerere University

Rachael Nakiganda

Makerere University

Rachael Ndyabawe

Makerere University

Jonathan Nkalubo

Mulago National Referral Hospital

Nelson Ssewante

Makerere University

Felix Bongomin

Gulu University

Sabrina Bakeera-Kitaka

Makerere University

Research Article 
Keywords: Research, Undergraduate, Health, Students, Uganda

Posted Date: November 8th, 2021

DOI: https://doi.org/10.21203/rs.3.rs-1036706/v1

License: (c) (1) This work is licensed under a Creative Commons Attribution 4.0 International License. Read Full License

Version of Record: A version of this preprint was published at BMC Medical Education on April 6th, 2022. See the published version at https://doi.org/10.1186/s12909-022-03320-y. 


\section{Abstract}

Background: Involvement of undergraduate health professions students (HPS) in research will facilitate evidence-based clinical practice among future healthcare partitioners. This study aimed to assess research involvement of undergraduate students and associated factors in Uganda.

Methods: A cross-sectional study was conducted using an online assessment tool sent through WhatsApp groups and E-mail addresses of HPS in 12 medical schools in Uganda between $20^{\text {th }}$ September and $5^{\text {th }}$ October 2021.

Results: We enrolled 398 participants with a mean age of $23.9 \pm 3.7$ years. Of this, $267(67.1 \%)$ were male. One hundred twenty (30.2\%) participants previously participated in a research activity: $90(58.4 \%)$ as research assistants, 39 (25.3\%) published as first authors, and 25 (16.2\%) as co-authors. Training on the conduct of research was received by242 (65.8\%) participants, and $326(81.9 \%)$ had intentions of conducting research in the future. Factors influencing participation in research activities were, age ${ }^{3} 25$ years (adjusted odds ratio (aOR): 1.9, 95\% confidence interval (95\% $\mathrm{Cl}): 1.2-3.2, \mathrm{p}=0.012)$, being male (aOR: 2.1, 95\%Cl: 1.2 - 3.6, p=0.008), and being in a clinical year i.e., year 3 (aOR: 3.2, 95\% Cl: 1.1 -9.3, $\mathrm{p}=0.033$ ), year 4 (aOR: 3.3, 95\% Cl: 1.1 - 9.5, $p=0.028$ ) and year 5(aOR: 11.6, 95\% Cl: $3.2-42.1, p<0.001$ ). Lack of funds (79.6\%), and mentorship (63.3\%) were reported as major barriers to research.

Conclusions: Despite a high proportion of HPS showing interest in getting involved in research, less than one-third reported previous involvement. Addressing barriers such as funding could potentially improve research involvement and output among undergraduate HPS in resource-limited settings.

\section{Background}

Globally, medical research and innovation remains a basic cornerstone upon which new advancements and guidelines in clinical practice are based (1). Provision of adequate health care services for the best patient management outcomes is pivoted on the interplay between physician-scientists whose work is more dedicated to carrying out medical research and clinicians who are mainly in direct patient care (2). A balance between these two professions is therefore crucial for continuous delivery of evidence-based care (3). Unfortunately, the medical field is still and has for decades suffered a global shortage of physician-scientists (3-5), a problem which if not curbed early could retard progress in evidence-based clinical practice (2).

Medical school students are generally looked at as the primary pool from which emerge majority of the various health care professionals, clinicians, and physician scientists inclusive. However, a great tendency to prefer clinical practice to medical research as a career has been reported among many medical students worldwide (6-7), which is the commonest cause of insufficient physician-scientists. Delayed exposure to research during undergraduate medical training has been a commonly reported reason for this imbalance (8-9). Though the primary objective of undergraduate medical education is to train students in providing safe and effective patient care (10-11), the expeditious advancements in the 
health care system and the increasing amount of easily accessible information demand that physicians make decisions based on reliable scientific evidence (11).

Sub-Saharan Africa (SSA) has continued to suffer the world's biggest burden of disease and mortality. This has been linked to its suboptimal quality of health care delivery, which is fueled by insufficient research evidence (12). Evidence can only be derived through carrying out high standard quality research to generate local data based on common health problems that can be used to inform guidance (12). Despite employing various interventions to boost research such as incorporating research methods into education curriculum by many African countries(13-14), the overall research output from SSA is still low (15). This paucity of research has led to over dependence by many African countries' clinical practice on research findings from developed countries, which has different disease burden and level of medical advances compared to SSA. This could result in undesirable outcomes as observed in West Africa where shortage of skilled clinical scientists just fueled disease progression and mortality instead of its containment during the Ebola virus disease outbreak (16).

In Uganda, despite the increasing number of medical schools in the last two decades from only two in 2003 to now 12 in 2021(17), the volume of undergraduate research output has slightly improved, but still very low. In 2003, research done at one public medical school reported that the major barriers for students to do undergraduate research were lack of collaborations, lack of guidance and lack of funding. However, this study was done 18 years ago when the country had only two medical schools and involved only one medical school (18).

Because different medical schools may operate on different curricular, timetables, and administrative bodies, it is critical to know whether similar factors exist currently in other public and private universities, or they differ and in the different health care $(\mathrm{HC})$ courses offered. Therefore, in this study, we aimed to assess research involvement of undergraduate students exploring awareness, barriers and motivators in all 12 medical students in Uganda

\section{Methods}

\section{Study design}

Between $20^{\text {th }}$ September and $5^{\text {th }}$ October 2021, we conducted an online, descriptive and cross-sectional study across 12 universities in Uganda.

\section{Study area and setting}

The study was conducted in Uganda. There are currently 54 universities in Uganda turning out over 40,000 graduates annually. However, only 12 universities offer health professional courses with an estimated population of 10,000 students. These include both private and public medical schools and they are Makerere University (MAK), Mbarara University of Science and Technology (MUST), Busitema University (BU), Kabale University (KU), Gulu University (GU), Kampala International University (KIU), King 
Caesar University (KCU), Uganda Christian University (UCU), Muni University, Soroti University, Lira University, and Islamic University in Uganda (IUIU). MAK, GU, BU, MUST, Muni, Kabale and Soroti are public universities whilst the rest are private.

\section{Target population}

All undergraduate students, 18 years or older, from year 1 to year 5 of study pursuing a health profession program at any of the above-mentioned universities. Programs included were Bachelor of Medicine and Surgery (MBChB), Bachelor of Biomedical Sciences (BSB), Bachelor of Nursing/Midwifery (BSN/MW), Bachelor of Pharmacy (BPHARM), Bachelor of Dental Surgery (BDS), Bachelor of Medical Radiography (BMR), Bachelor of Science in Anesthesia (BSA), among others.

\section{Sample size}

A sample size of 420 participants was calculated using the modified Kish-Leslie formula for infinite population, with a prevalence of $50 \%$, margin of error of $5 \%$ at $95 \%$ confidence interval, and a $10 \%$ nonresponse rate.

\section{Study variables}

The independent variables included were sex, age, year of study, university of study, type of university ownership and program of study. Dependent variables included questions on students' awareness about research, attitudes, anticipated motivational factors and barriers for research involvement.

\section{Data collection tool:}

The questionnaire used had 33 questions and was adopted from previously validated questionnaires by Sayedalamin et al (19) and Lloh et al (20).It consisted of 5 sections as below:

Section I. Had 7 Questions about participants' demographics.

Section II. Had 10 questions assessing for participants' awareness about Research

Section III. Had 9 questions, assessing for participants' attitudes towards research.

Section IV. Had 3 questions, assessing for participants'perceived motivational factors and benefits for engaging in research.

Section V. Had 4 questions, assessing for participants' perceived barriers for research involvement and intentions of doing research as a career.

\section{Data collection procedure}

Data was collected by convenience sampling method. The link to the online questionnaire was sent to eligible participants via WhatsApp groups and personal inboxes plus email addresses. It was a self- 
administered questionnaire written in simple English for effective understanding by the participants.

\section{Quality Assurance}

The questionnaire was pre-tested among 15 undergraduate students from the College of Veterinary Medicine, Makerere University, and the identified corrections necessary were made before administering the tool to the final study participants. The questionnaire had check points that ensured that only completed forms could be submitted, and that each articipant could submit only one response form, hence excluding duplication of responses from participating more than once.

\section{Data management and analysis}

Upon completion of data collection, entries were downloaded. Data cleaning and coding were done using Microsoft Excel 2016 and coded data exported to STATA 15.0 for analysis. Demographic characteristics, awareness, barriers, benefits, and motivational factors to participate in research were first summarized as in tables with frequencies and percentages for categorical variables and mean and standard deviation for numerical variables. Attitude was summarized on a figure format. Associations between independent and dependent variables were assessed using Chi-square or Fisher's exact tests for categorical data and Mann-Whitney $U$ test for numerical data. Multivariable logistic regression was performed adjusting for all important confounders. Results were presented as adjusted odds ratio (aOR) and 95\% confidence interval $(95 \% \mathrm{Cl})$. A $p<0.05$ was considered statistically significant.

\section{Results}

A total of 406 responses were obtained. After data cleaning, 398 entries were eligible for analysis (response rate, 398/420 (95\%)).

\section{Demographic characteristics of respondents}

Of the 398 respondents, 267 (67.1\%) were male, 220 (55.3\%) were pursuing MBChB, and 307 (77.1\%) were from public universities (Figure 1). The mean age of the respondents was $23.9 \pm 3.7$ years. Other demographic characteristics are presented in Table 1.

\section{Awareness about Research}

Most $(92.7 \%, n=369)$ respondents had ever heard of the concept of medical research and $297(80.7 \%)$ knew a colleague who had participated in research. One-hundred and twenty $(32.6 \%)$ respondents had personally participated in research outside academic requirements. Of this, 90 (58.4\%) participated as research assistants, $39(25.3 \%)$ as principal investigators and $25(16.2 \%)$ as co-investigators. Of those that had participated in research before this survey, 27 (22.5\%) had published a paper in a peer-reviewed journal. Twenty-one (70\%) of the 27 publications were in international journals. 
With regard to research-related training, 242(65.8\%) respondents reported to have had prior training in proposal writing, $101(27.4 \%)$ manuscript writing and 68(18.5\%) publication process (Table 2).

\section{Attitudes towards undergraduate research.}

Three hundred and twenty-five (81.6\%) respondents strongly agreed that research is an important aspect in human health, and that it plays a significant role in making clinical decisions and policies $(n=306$, $76.1 \%)$. Majority $(n=349,87.6 \%)$ also believed that undergraduate research can have a significant impact on the health system of the country and $243(61.1 \%)$ were open to taking on research in their future careers (Figure 2)

\section{Motivational factors and perceived barriers to participation in research}

Personal development ( $n=300,75.4 \%)$, contribution to patient care $(n=294,73.9 \%)$, gaining experience $(n=266,66.8 \%)$, collaboration with senior researchers $(n=244,61.3 \%)$ and developing a robust Curriculum Vita $(n=226,56.8 \%)$ were the most reported motivating factors for participation in research by respondents (Table 3 ).

Participants reported lack of funds ( $n=317,79.6 \%)$, lack of mentorship $(n=252,63.3 \%)$, collaboration opportunities ( $n=201,50.5 \%$ ) as the major barriers to their participation in research (Table 4). Majority of participants $(n=168,42.2 \%)$ reported difficulties in study designing and manuscript writing $(n=155$, $38.9 \%)$.

Likewise, participants believed that they would participate in research if funding ( $n=303,76 \%)$, mentorship ( $n=288,72.2 \%$ ), research training $(n=240,60.0 \%)$ were availed to them. Otherwise, majority of participants $(n=326,81.9 \%)$ had intentions of doing research in future.

\section{Factors associated with research involvement}

On bivariate analysis (Table 1$)$, age $(p<0.001)$, sex $(p=0.002)$ and year of study $(p<0.001)$ were significantly associated with participation in research activities.

Table 1 indicates that participants 25 years or older had nearly 2-fold higher odds of taking part in research activities than younger colleagues (aOR: 1.9, 95\% Cl: $1.2-3.2, p=0.012$ ). Male participants had 2.1-fold higher odds of being more engaged in research than their female counterparts (aOR: $2.1,95 \% \mathrm{Cl}$ : 1.2 - 3.6, $p=0.008$ ). Additionally, participants in higher years had higher odds of participating in research compared to first year students with increasing odds i.e., year 3 (aOR: 3.2, 95\% Cl: $1.1-9.3, p=0.033$ ), year 4 (aOR: 3.3, 95\% Cl: 1.1 - 9.5, p=0.028) and year 5(aOR: 11.6, 95\% Cl: $3.2-42.1, p<0.001$ ).

\section{Discussion}

This study, aimed at assessing the awareness, attitude, motivation factors and barriers to research involvement among health professional students in Uganda revealed that over three-quarters of 
respondents were aware of medical research and with a positive attitude towards it. The major motivators for research involvement were the desire for personal development and contributing towards patient care, while lack of funds and mentorship were the main barriers for the majority.

The very high awareness (92.7\%) and positive attitude towards research reported in this study could be possibly because most medical schools in the country have course units on research methods incorporated in their curricular. In addition, the introduction of programs aimed at boosting undergraduate research at a few medical schools such as the Health Professionals Education Partnership Initiative (HEPI) at Makerere, Busitema and Kabale Universities have tried to expose students to more research work outside the one they do for their academic requirements.

Our finding agrees with that reported by previous studies where more than half of participants reported to be aware about research (20-21) and had positive attitude towards it (21-22), but in contrast with that by Chellaiyan and colleagues in India (23) where less than a quarter of students had a positive attitude towards medical research. Such and more programs such as research results dissemination conferences aimed at exposing students to research are encouraged to better this awareness and positive attitudes. Despite this good awareness and attitude however, only one-third (32.5\%) of students had engaged in research activities outside their class research work. This could be to the fact that most medical schools have tight schedules with overwhelming workload that limits time for most students to engage in cocurricular activities including research. This finding is almost like one reported in India where only $34.3 \%$ of students had engaged in research activities (23). Mentorship on how to plan and balance classwork alongside co-curricular activities during medical school could help more students to actively engage in research work.

Our findings showed that less than one-fourth (22.5\%) of participants had published at least one research article, and this finding is similar to previous studies in India (23) and Sweden (10) that reported that only $15 \%$ and $17.4 \%$ students respectively had published their work in peer reviewed journals. However, this finding is Lower compared to one reported among medical practitioners in Nigeria (20) where more than one-fourth (34.3\%) of participants had published at least one article in a peer reviewed journal. Nevertheless, in our study, seventy percent of those who had published had done so in international journals as opposed to local or regional journals. This is possibly because more international journals waiver either partially or fully on article processing charges (APCs) for authors from low-income countries compared to regional journals. APCs have been reported in the past as one of the major factors considered by Authors from resource limited settings when choosing a journal to publish their articles from (20). Also, the perceived increased visibility and acknowledgement to the authors in international journals compared to local and regional journals could be another trigger for this preference.

Three-fourth of respondents were motivated to involve in research for personal development and contribution to patient care. This finding is congruent with that reported in Nigeria among medical practitioners (20) but in contrast with that by Pallampathy and others among students in India who reported personal interest, facilitation of foreign exams, and peer pressure as their main motivational 
factors for research involvement (24). Majority (80\%) of students expressed the desire to pursue a career in research. This outcome is like those reported in South Africa (25) and England (26), where majority of students exhibited a high interest in doing research as a career. With such high interests kept to implementation, more research scientists will be anticipated in future and could lead to tremendous advancements in evidence-based medical practice, hence improved quality, and outcomes of patient care. Concerned stake holders such as medical education heads, ministry of health and other drivers of the health care system are recommended to take appropriate supportive interventions for such dreams to remain vibrant and with the motivation for better health.

Majority of respondents reported lack of funds, mentorship, and collaboration as the perceived barriers to research involvement. This could be because currently, there are generally very few research grants for undergraduate students both locally and globally, the generally suboptimal mentorship programs in most Ugandan universities, as well as the relatively bigger age gap between the famous research scientists in the country and the students. This result is congruent with that found in Malaysia that reported lack of skills and funding (27) but in contrast with that reported among medical students in India who reported difficulty in choosing a topic, collecting data, lack of time (23) and difficulty in follow up of patients (24) as the major barriers. Improvement in early mentorship in medical schools as already suggested by participants in the study by Munabi and colleagues (28) could help in curbing such obstacles

We also report that participants aged 25 years or older, being male, and in a higher academic year of study had higher odds of being involved in research compared to those younger than 25 years, females, and being in lower year of study, respectively. This is possibly because participants at a higher age and class of study have had more exposure to the various medical disciplines including research course units, seen and interacted with senior researchers in the field, hence more chances of obtaining inspiration, mentorship, and collaboration for active research. Also, they have adapted to the general medical school pressure and can easily plan well to balance their academics with co-curricular activities including research- a very time requiring activity. This finding concurs with that reported by Kyaw and colleagues in Malaysia (27) and another in Sweden (10) where students of older age and in higher years of study were more knowledgeable about research than the younger and in lower years of study. It also agrees with various studies that found a higher correlation between male sex and research involvement (25-26). However, it contrasts with that reported in Saudi Arabia where age above 25 years was associated with less involvement in research (20).

Our study has some important limitations. Firstly, we used convenience method hence only responses from respondents who could manage to answer the online questionnaire were captured, and they may not be the actual representative of all health profession students in the country. Secondly, the results are based on participants' self-reported answers without proof confirmation by the investigators, such as one's total number of publications and the journals used, hence liable to possibility of recall bias and telling lies. However, it is a nationwide study, covering all the 12 medical schools and their respective programs of study in the country, with significant representation from each medical school, hence these results can be generalized. 


\section{Conclusion}

Despite the massive awareness for and good attitude towards research among the respondents, active research involvement and publication is still very low. Lack of funding and mentorship are the perceived barriers to research involvement. Future investments in small grant acquisition, research training and mentorship programs are recommended.

\section{Abbreviations}

APCs: $\quad$ Article Processing Charges

COVID-19: Coronavirus disease-2019

HEPI: $\quad$ Health Professional Education Partnership Initiative

HPS: $\quad$ Health Profession Student

MAKCHS: Makerere University, College of Health Sciences

MBChB: Bachelor of Medicine and Bachelor of Surgery

MHREC: Mulago Hospital Research and Ethics Committee

SSA: $\quad$ Sub-Saharan Africa

\section{Declarations}

\section{Ethical approval and consent to participate}

Mulago Hospital Research and Ethics Committee (MHREC) approved the study protocol (refence number: MHREC 2126). Mulago Hospital is the teaching hospital for Makerere University college of health sciences (MAKCHS) and its Research and Ethics Committee is authorized to approve any research done by students from MAKCHS. Informed consent was sought from each participant before taking part in the study. This was effected by requesting the participant to click on the "I accept to participate" option at the end of the consent statement on the study tool before starting to answer the questionnaire. The study was conducted in accordance with the Declaration of Helsinki.

\section{Consent for Publication}

Not applicable

\section{Availability of data and materials}

The datasets used and/or analyzed during the current study are available from the corresponding author on reasonable request. 


\section{Competing interest}

The authors declare that they have no competing conflicts

\section{Funding}

No funding was received from any institution, organization, or company for the production of this work.

\section{Authors' contributions}

B.K., L.A., R.N., I.A., J.K., D.B., A.S.N., R.Ng., R.Nd., J.N., N.S., F.B. and S.B.K. made substantial contributions towards this work. All authors took part in the conceptualization and designing of the study. B.K., L.A., R.N., I.A., J.K., D.B., A.S.N., R.Ng., R.Nd., J.N., and F.B. collected data and drafted the manuscript. N.S. analyzed the data, while B.K., F.B. and S.B.K. critically revised the article for final important intellectual content. All the authors agreed to submit the work to this journal and agree to be accountable for all aspects of this work.

\section{Acknowledgement}

We commend the following people who assisted us in data collection from the different medical schools. Asaph Asiimwe (Soroti University), Nagaba Grace (Kabale University), Mbulaka Remigious (Uganda Christian University) Stuart Kitandwe (MAKCHS) Muhangi Jimmy (Kabale University), Nabyonga Esther (Busitema University), Niwamanya Edwin (Kampala International University) and Kafuko Josephat (Kabale University).

The authors gratefully thank all respondents for their time and internet data spared to participate in this study. This study was conducted by the MAKCHS Research and Writers' club (MAKCHS-RWC).

The authors declare no competing interests in this work.

\section{References}

1. Al-Shalawy FAN, Haleem A. Knowledge, attitudes and perceived barriers towards scientific research among undergraduate health sciences students in the central province of Saudi Arabia. Educ Med. 2015,7:16-21

2. Mahmood Shah SM, Sohail M, Ahmad KM, Imtiaz F, Iftikhar S. Grooming Future Physician-scientists: Evaluating the Impact of Research Motivations, Practices, and Perceived Barriers Towards the Uptake of an Academic Career Among Medical Students. Cureus. 2017 Dec 27,9(12):e1991. doi: 10.7759/cureus.1991. PMID: 29503785, PMCID: PMC5828671.

3. Ommering BWC, Wijnen-Meijer M, Dolmans DHJM, Dekker FW, van Blankenstein FM. Promoting positive perceptions of and motivation for research among undergraduate medical students to stimulate future research involvement: a grounded theory study. BMC Med Educ. 2020 Jun 26,20(1):204. doi: 10.1186/s12909-020-02112-6. PMID: 32586311, PMCID: PMC7318757. 
4. Milewicz DM, Lorenz RG, Dermody TS, Brass LF, National Association of MD-PhD Programs Executive Committee. Rescuing the physician-scientist workforce: the time for action is now. J Clin Invest. 2015 Oct 1,125(10):3742-7. doi: 10.1172/JCl84170. Epub 2015 Oct 1. PMID: 26426074, PMCID: PMC4607120.

5. Ommering BWC, van Blankenstein FM, Wijnen-Meijer M, van Diepen M, Dekker FW. Fostering the physician-scientist workforce: a prospective cohort study to investigate the effect of undergraduate medical students' motivation for research on actual research involvement. BMJ Open. $2019 \mathrm{Jul}$ 23,9(7):e028034. doi: 10.1136/bmjopen-2018-028034. PMID: 31340963, PMCID: PMC6661705.

6. Rashid KA, Gomathy S, Manan A. The involvement of doctors in research activities of in two major hospitals in Penang, Malsaysia. MJPHM. 2012,12:31-38. [Google Scholar]

7. Imafuku R, Saiki T, Kawakami C, Suzuki Y. How do students' perceptions of research and approaches to learning change in undergraduate research? Int J Med Educ. 2015 Apr 12,6:47-55. doi: 10.5116/ijme.5523.2b9e. PMID: 25863495, PMCID: PMC4395208.

8. Goldhamer ME, Cohen AP, Bates DW, Cook EF, Davis RB, Singer DE, Simon SR. Protecting an endangered species: training physicians to conduct clinical research. Acad Med. 2009 Apr,84(4):43945. doi: 10.1097/ACM.0b013e31819a7cb1. PMID: 19318774.

9. Weaver AN, McCaw TR, Fifolt M, Hites L, Lorenz RG. Impact of elective versus required medical school research experiences on career outcomes. J Investig Med. 2017 Jun,65(5):942-948. doi: 10.1136/jim-2016-000352. Epub 2017 Mar 7. PMID: 28270407, PMCID: PMC5833985.

10. Möller R, Shoshan M. Medical students' research productivity and career preferences, a 2-year prospective follow-up study. BMC Med Educ. 2017 Mar 3,17(1):51. doi: 10.1186/s12909-017-0890-7. PMID: 28253880, PMCID: PMC5335804.

11. Frenk J, Chen L, Bhutta ZA, Cohen J, Crisp N, Evans T, Fineberg H, Garcia P, Ke Y, Kelley P, Kistnasamy B, Meleis A, Naylor D, Pablos-Mendez A, Reddy S, Scrimshaw S, Sepulveda J, Serwadda D, Zurayk H. Health professionals for a new century: transforming education to strengthen health systems in an interdependent world. Lancet. 2010 Dec 4,376(9756):1923-58. doi: 10.1016/S0140-6736(10)618545. Epub 2010 Nov 26. PMID: 21112623.

12. Ngeh EN. Research among undergraduate biomedical students in Cameroon: contextual barriers, room for improvement. Pan Afr Med J. 2019 Jun 27,33:149. doi: 10.11604/pamj.2019.33.149.18807. PMID: 31558946, PMCID: PMC6754834.

13. Robyn L. Houlden, Jamila B. Raja, Christine P. Collier, Albert F. Clark \& Jennifer M. Waugh (2004) Medical students' perceptions of an undergraduate research elective, Medical Teacher, 26:7, 659-661, DOI: 10.1080/01421590400019542

14. M. F. Griffin \& S. Hindocha (2011) Publication practices of medical students at British medical schools: Experience, attitudes and barriers to publish, Medical Teacher, 33:1, e1-e8, DOI: 10.3109/0142159X.2011.530320

15. Langer A, Díaz-Olavarrieta C, Berdichevsky K, Villar J. Why is research from developing countries underrepresented in international health literature, and what can be done about it? Bull World Health 
Organ. 2004 Oct,82(10):802-3. PMID: 15643806, PMCID: PMC2623037.

16. Adefuye AO, Adeola HA, Bezuidenhout J. The physician-scientists: rare species in Africa. Pan Afr Med J. 2018 Jan 4,29:8. doi: 10.11604/pamj.2018.29.8.13239. PMID: 29632630, PMCID: PMC5889513.

17. "List of medical schools in Uganda - Wikipedia" https://en.m.wikipedia.org/wiki/List_of_medical_schools_in_Uganda

18. Munabi IG, Katabira ET, Konde-Lule J. Early undergraduate research experience at Makerere University Faculty of Medicine: a tool for promoting medical research. African

19. Sayedalamin Z, Halawa TF, Baig M, Almutairi O, Allam H, Jameel T, Gazzaz ZJ, Atta H. Undergraduate medical research in the Gulf Cooperation Council (GCC) countries: a descriptive study of the students' perspective. BMC Res Notes. 2018 May 8,11(1):283. doi: 10.1186/s13104-018-3381y. PMID: 29739473, PMCID: PMC5941694. Health Sciences (AJOL) 2006,6(3):182-186.

20. Pascal Iloh GU, Amadi AN, Iro OK, Agboola SM, Aguocha GU, Chukwuonye ME. Attitude, practice orientation, benefits and barriers towards health research and publications among medical practitioners in Abia State, Nigeria: A cross-sectional study. Niger J Clin Pract. 2020 Feb,23(2):129137. doi: 10.4103/njcp.njcp_284_18. PMID: 32031085.

21. Meraj L, Gul N, Zubaidazain, Akhter I, Iram F, Khan AS. Perceptions and attitudes towards research amongst medical students at Shifa College of Medicine. J Pak Med Assoc. 2016 Feb,66(2):165-89. PMID: 26819161

22. Alsaleem SA, Alkhairi MAY, Alzahrani MAA, Alwadai MI, Alqahtani SSA, Alaseri YFY, Alqarni MAM, Assiri SA, Alsaleem MA, Mahmood SE. Challenges and Barriers Toward Medical Research Among Medical and Dental Students at King Khalid University, Abha, Kingdom of Saudi Arabia. Front Public Health. 2021 Aug 20,9:706778. doi: 10.3389/fpubh.2021.706778. PMID: 34490190, PMCID: PMC8417604.

23. Chellaiyan VG, Manoharan A, Jasmine M, Liaquathali F. Medical research: Perception and barriers to its practice among medical school students of Chennai. J Educ Health Promot. 2019 Jul 29,8:134. doi: 10.4103/jehp.jehp_464_18. PMID: 31463319, PMCID: PMC6691744.

24. Pallamparthy S, Basavareddy A. Knowledge, attitude, practice, and barriers toward research among medical students: A cross-sectional questionnaire-based survey. Perspect Clin Res. 2019 AprJun,10(2):73-78. doi: 10.4103/picr.PICR_1_18. PMID: 31008073, PMCID: PMC6463502.

25. Bovijn J, Kajee N, Esterhuizen TM, Van Schalkwyk SC. Research involvement among undergraduate health sciences students: a cross-sectional study. BMC Med Educ. 2017 Oct 16,17(1):186. doi: 10.1186/s12909-017-1025-x. PMID: 29037185, PMCID: PMC5644181.

26. Burgoyne LN, O'Flynn S, Boylan GB. Undergraduate medical research: the student perspective. Med Educ Online. 2010 Sep 10,15. doi: 10.3402/meo.v15i0.5212. PMID: 20844608, PMCID: PMC2939395.

27. Kyaw Soe HH, Than NN, Lwin H, Nu Htay MNN, Phyu KL, Abas AL. Knowledge, attitudes, and barriers toward research: The perspectives of undergraduate medical and dental students. J Educ Health Promot. 2018 Feb 9,7:23. doi: 10.4103/jehp.jehp_61_17. PMID: 29629384, PMCID: PMC5852981. 
28. Munabi IG, Buwembo W, Joseph R, Peter K, Bajunirwe F, Mwaka ES. Students' perspectives of undergraduate research methods education at three public medical schools in Uganda. Pan Afr Med J. 2016 May 24,24:74. doi: 10.11604/pamj.2016.24.74.9410. PMID: 27642414, PMCID: PMC5012756.

\section{Tables}

Table 1: Participants' characteristics that influence participation in research activities 
Variable

Total

Age

$<25$

$\geq 25$

Mean (SD)

Sex

\begin{tabular}{l} 
Female \\
Male \\
\hline Course
\end{tabular}

MBChB

BDS

BNUR

BPARM

Others

Year of study

Year 1

Year 2

Year 3

Year 4

Year 5

University ownership

Private

Public

\section{Student funding status}

Government funded

Private funded

\section{Total \\ Participation in research(bivariate)}

$\mathbf{N}(\%) \quad$ Yes, n (\%) No, n (\%)
Participation in research (BLR) $\begin{array}{lll}\mathrm{P}- & \text { Odds ratio }(95 \% & \begin{array}{l}\mathrm{p}- \\ \text { value }\end{array} \\ \mathrm{Cl})\end{array}$ $398(100) \quad 120(32.5) \quad 249(67.5) \quad$ N/A 0.001

\begin{tabular}{llll}
\hline $302(75.9)$ & $78(28)$ & $201(72)$ & \\
\hline $96(24.1)$ & $42(46.7)$ & $48(53.3)$ & \\
\hline $23.9(3.7)$ & $24.6(3.5)$ & $23.5(3.8)$ & $<0.001$ \\
& & & 0.002
\end{tabular}

Reference

1.9(1.2-3.2)

0.012 
Table 2: Responses to awareness questions 
Question

Frequency Percent

Have you ever heard about medical research? $(\mathrm{N}=398)$

Yes

369

No

29

7.3

Know an undergraduate colleague that have participated in research?

$(\mathrm{N}=398)$

Yes

297

80.7

No

71

19.3

Ever participated in any research activity outside your academic requirement? $(\mathrm{N}=398)$

Yes

120

32.5

No

249

67.5

What was your role in that study? $(\mathrm{N}=120)$

Research Assistant

First Author

Co-Author

Ever published any research paper in a peer-reviewed journal? $(\mathrm{N}=120)$

Yes

No

If yes, how many articles? ( $\mathrm{N}=27)$

1 article

2 articles

3 or more articles

Have you had any first-author publication? ( $N=27)$

Yes

No

What kind of journal was your paper(s) published? ( $N=27)$

International

Regional

Local
11

16

27

93

22.5

77.5

14

51.9

6

22.2

7

25.9

40.7

59.3

21

70

2

6.7

7

23.3 
Have you had any training on research proposal writing? ( $\mathrm{N}=398)$

Yes

No

Have you had any training on manuscript writing? $(\mathrm{N}=398)$

Yes

No

Have you had any training on journal publication process? $(\mathrm{N}=398)$

Yes

68

18.5

No

300

81.5

Table 3: Motivational factors and perceived benefits of participating in research 
Question, $\mathrm{N}=398$

Frequency Percentage

What do you hope to benefit from conducting research?

Personal development

300

75.4

Acknowledgement

172

43.2

Monetary rewards

149

37.4

Contribution to patient care

294

73.9

Experience

266

66.8

Collaboration with senior researchers

244

61.3

Developing your $\mathrm{CV}$ by having many research papers

226

56.8

Increasing acceptability into a residency program

191

48

Passion

192

48.2

Others

4

1

What kind of assistance do you need to improve your research participation?

Funding 303

76.1

Guidance on research topic selection

242

60.8

Early exposure

216

54.3

Research training

240

60.3

Providing supervisor volunteers

146

36.7

Mentorship

288

72.4

Facilitating institutional review

108

27.1

Creating a suitable environment

134

33.7

Collaboration with other researchers

184

46.2

Easing ethics approval

109

27.4

Guidance on manuscript writing

183

46

Guidance on publication of results

149

37.4

Avenues for presentation of research findings

145

36.4

Others

1

0.3

Do you have any intentions of doing research in your future career? 
Table 4: Barriers to participation in research 
What factors would limit you from conducting research?

Lack of mandatory courses on research methodology

Lack of time for research conduction

Lack of funds

Lack of collaborations 201

50.5

Lack of interest in research

$$
55
$$

Lack of statistical support

Lack of mentorship 252

Difficulty in dealing with patients 45

Difficulty in obtaining approval for the study

Others

What are the commonest challenges you usually find when carrying out research?

Lack of mentorship

Lack of motivation

Lack of time

Complexity of the research process

Lack of opportunities like sponsorship

Others

\section{What type of research do you find difficult carrying out?}

Case Report

64

16.1

Basic science

47

Retrospective clinical study

Prospective clinical study

Clinical trial

Cross-sectional study

Review articles

Others
223

141

166

165

279

7
1.8

56

35.4

41.7

41.5

70.1

8

At which of the following steps of research do you find the biggest 
challenge?

Designing a study

168

42.2

Study sampling

85

21.4

Participant Recruitment

122

30.7

Biological statistics

121

30.4

Manuscript writing

155

38.9

Paper presenting

77

19.3

Others

12

3

Figures

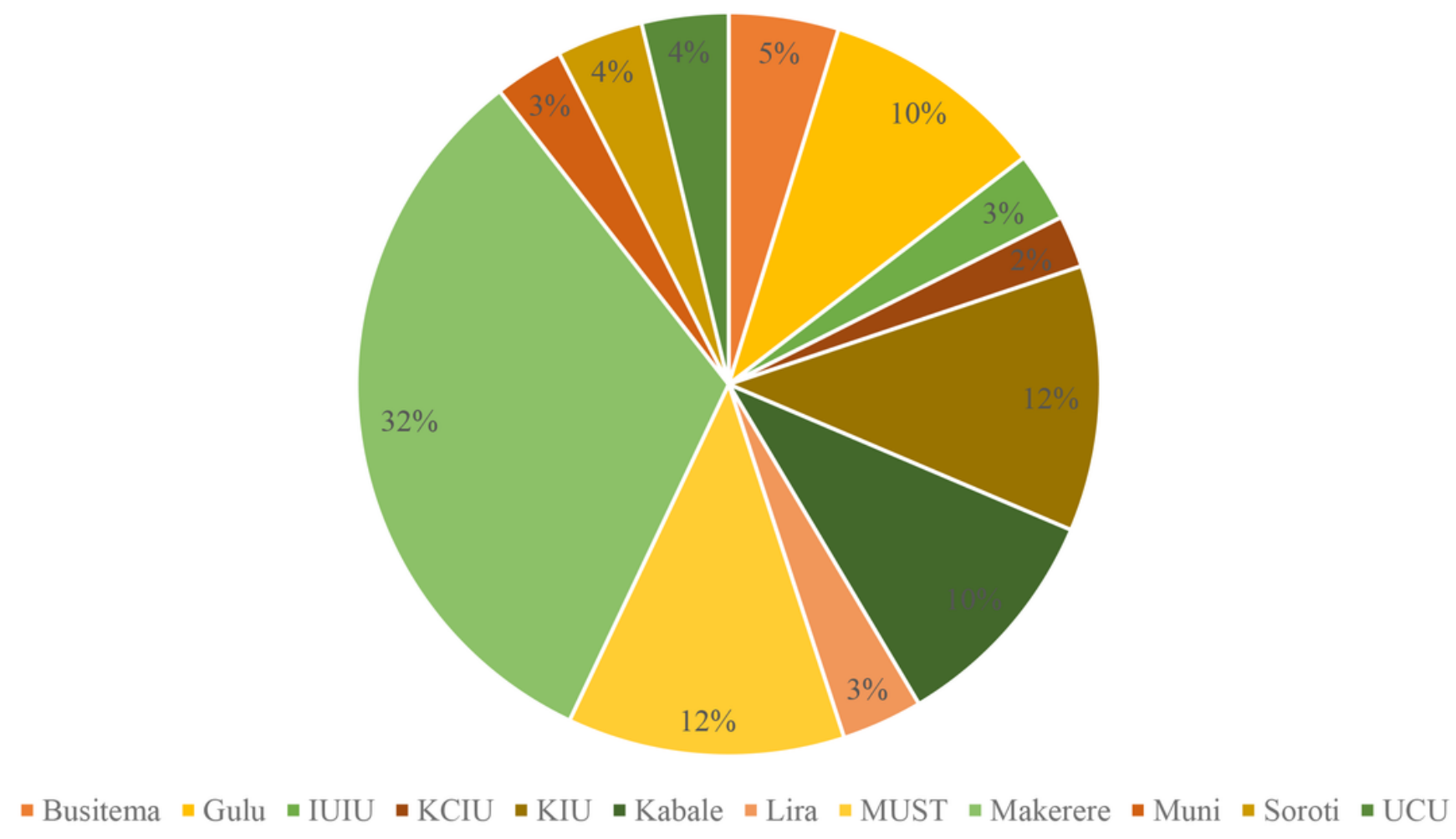

Figure 1

Distribution of participants across all the universities. 
Research is very important for Human Health

Research plays a very significant role in making clinical decisions, health policies

It is possible for undergraduate health professional student to participate in research

It is possible for undergraduates to publish in a peer-reviewed journal

Undergradute Research can have a significant contribution to the healthcare system

Students should only start research after joining postgraduate studies

I am interested in doing research at my undergraduate level

Research is very important for health professional students

In the future, I want to be established in research as my career
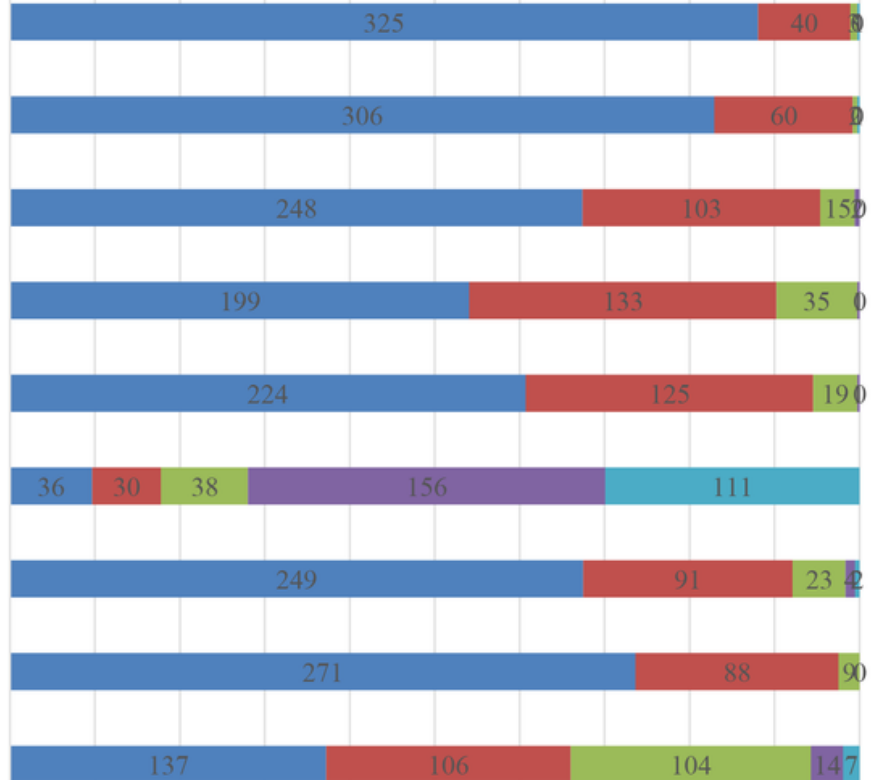

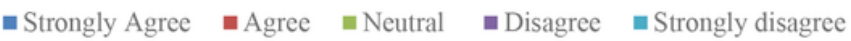

\section{Figure 2}

\section{Attitude towards undergraduate research}

